\title{
On the Active Struggle of Children's Novels in "Strange Tales of a Lonely Studio"
}

\author{
Yang Yujun \\ Zaozhuang University, \\ Zaozhuang, Shandong 277160
}

\begin{abstract}
There are many children's novels in the famous collection of classical Chinese short stories in the early Qing Dynasty, for example "Strange Stories from a Lonely Studio". In these works, the author Pu Songling actively expresses the spirit of young hero's active struggling against evil forces and shapes the young hero's image of brave struggle. Through these children's works, it also indirectly shows Pu Songling's child education concept of active resistance and daring to resist.
\end{abstract}

Keywords-Strange Tales from a Lonely Studio; Pu Songling; Children's novels; Struggle spirit; Children's Education View

\section{INTRODUCTION}

In the early Qing Dynasty, the famous novelist $\mathrm{Pu}$ Songling's "Strange Stories from a Lonely Studio" is a collection of colorful and all-encompassing short stories in classical Chinese. Of all the nearly 500 works in " Strange Stories from a Lonely Studio", many chapters directly reflect the lives of children or teenagers, and can be called children's novels. Jiang Feng's "History of Modern Chinese Children's Literature" said: "Pu Songling has been unsuccessful in science and has been a teacher for more than 30 years. He lives with children every day. He loves children and life, and is also familiar with children's psychology and children's language. Therefore, the image of the child appearing in his writings is vivid and vivid. "[1]

In these children's novels, $\mathrm{Pu}$ Songling has created a group of vivid and radiant children's images. In these children's images, Pu Songling has placed and displayed many beautiful qualities, such as obsessive filial piety, sincere friendship, like Zhang Cheng. Zhang Cheng in the "goodness", kindness and righteousness, such as the young girl of the county in "Orange Tree", Xia Pingzi in "Cao Lei", etc.; wise and sensible, such as the Pearl in "Pearl"; diligent reading, Such as the big man in "The Big Man". The spiritual quality of Pu Songling's positive resistance in the image of children is especially worthy of our attention. "Yu Jiang", "Shang Sanguan" and "The Son of a Businessman" are excellent representatives in this respect.

\section{ACtive Struggle OF ChILDREN's Novels}

"Strange Tales from a Lonely Studio" as a " book of loneliness and indignation", the author $\mathrm{Pu}$ Songling has relentlessly exposed and satirized the dark politics, corrupt officials and evil forces of his time, just as Mr. Guo Moruo said in his couplet, " Writing ghosts and writing demons is superior to others. As "three points to the marrow, three points to the marrow" shows its distinctive theme of resistance, and this theme is also clearly reflected in the creation of its children's novels.

The theme of the struggle of $\mathrm{Pu}$ Songling's children's novels is reflected in the following aspects:

\section{A. Fighting against the evil forces in nature, "Yu Jiang" and} "Snakes" are representatives.

"Yu Jiang" is short, less than 400 words, and can be called a micro-fiction, but in a limited space, Pu Songling has shaped the image of a 16-year-old hero, Yu Jiang, who avenged his father and murdered the wolf. Yu Jiang revenge for the father who was killed by the wolf, and even the three wolves, have the courage to be conscientious and calm and sophisticated. In order to deal with the ferocious and awkward wolf, Yu Jiang adopted the strategy of "installing dead and killing wolves":

There are few rooms, one wolf, and the singer, the river does not move. Nothing, shaking his tail and sweeping his forehead, and gradually swaying his shares, the river does not move. When you are leaping forward, you will be swayed. Jiang Jiu hammered the wolf's brain and stood up. Start in the grass. Less, another wolf, as before, and stunned. ... Suddenly a wolf comes, bites his foot, and drags it. A few steps, spine meat stone skin. If Jiang is dead, the wolf is placed on the ground, meaning will be abdomen. Jiang suddenly hammered, servant; and even hammered, hehe.

In a simple language, $\mathrm{Pu}$ Songling wrote the young, courageous, brave and brave of the young Yujiang. He praised in the "Different Shishi" at the end of the article: "The farmer flow, there is this British thing!" Yilie is born in bloody, not straightforward. Wisdom is also different. "The Qing Dynasty, but Ming Lun, when Jiang Yan died in the wolf, commented: "The enemy is not driven by the enemy, the old is holding the weight, it is said to be talented. "[2] When Jiang killed the third wolf, that is, the culprits who killed his father, he commented: "It is more dangerous, more conspiring, more determined, more 
old-fashioned, that is, powerful, unable to do this. What is the child? Alas! What is Wei Wei! "[2]

"Snakes " is a thrilling story about a young man rescuing his brother from the mouth of a boa constrictor.Hu Tiancun $\mathrm{Hu}$ surnamed, brothers picking, deep into the valley. In the case of a giant scorpion, the brother was swallowed in front of him, and the younger brother rushed to see him, and his brother was smothered, and his anger was out of the axe. The first injury was swallowed up. Although the head is no longer, fortunately, the shoulder can not be down. The younger brother was extremely ruthless, but he was both brave and arrogant. He also took pains. Depending on the brother, the nose is full and you will be exhausted. I am shouldering the burden, and I will start at home when I have more than ten interest. Healing for half a year. To this day, the face is scarred, and the nose is only a hole. Alas! Among the farmers, there are brothers who are so embarrassed! Or saying: "It doesn't hurt, it is the feeling of virtue. "Really!

In the novel, although $\mathrm{Pu}$ Songling intends to show the power of filial piety through the article, the reader also looks down on Hu's brave and unafraid struggle against evil pythons and gives positive inspiration. If my brother gives up fighting against pythons and panics, or is defeated and escapes, my brother will surely die.

\section{B. Fight against evil forces in the real world}

"Shangguan Sanguan" is a famous chapter in "Strange Tales from a Lonely Studio", which depicts the touching story of a 36-year-old girl who is dressed up as a three-time official, revenge for the father, and defends the enemy.

The father of this novel, who wrote the third official, was ridiculed for being a bully by drunkenness and was beaten to death by the bully. The two brothers of the three officials complained for one year, but there was no result. The three officials of the Shang Dynasty determined to avenge their father. She first refused the husband's family request, and then persuaded her brother to bury her father. Later, the woman disguised as a man, fled at night, changed her name to $\mathrm{Li} \mathrm{Yu}$, and learned to play the game. After that, she won the opportunity to win the favor of the bully at the banquet. When she waited for the bully to sleep in the evening, she took the enemy and then resolutely succumbed. After the two bullies of the bully, they wanted to slay the corpse while guarding the body of the third official. They were killed by the three officials and the third official was never insulted even after his death.

As a young girl, the Shang Sanguan in the novel is both brave and brave, and it is extremely impressive. At the end of the novel, $\mathrm{Pu}$ Songling compares it to the famous ancient vengeful man, and thinks that the thorns of the king of the thorns are also inferior. He said: "There is a woman who does not know, but the brother For the husband, you can know. The "three officer being, namely, rustling xiao, also will be put to shame and do not flow, case ineffective and the ups and downs! I hope that the people in the world will buy silk embroidery, and their merits will not be reduced to Feng Zhuang. "I gave a very high evaluation.

\section{Fight against evil forces in the illusory world}

The protagonist of "The Son of a Businessman" is the son of a businessman who is ten years old and ten years old. He uses the great wisdom and bravery that ordinary people do not have, and kills the story of the fox demon that harms the human world. Jia's mother was ridden by the fox, and it became more and more serious. The family was invincible, and eventually the mother was dying, and the family was not allowed to approach her. He made up his mind to get rid of the fox. He pretended to play the game, but he carefully prepared it but he only cut off the tail of the fox. Later, I learned that the fox wanted a servant to buy wine. He poisoned the wine in advance and disguised himself as a fox servant. He sent the poisonous wine into the belly of the fox, and eventually the two foxes that harmed the good women. The demon is completely removed.

In the story, Jia Er's extraordinary wit left a deep impression on the readers, but Ming Lun's praise in the comments: "Ten-year-old children, why do you do this? It's awesome! The chest is well-founded, there is no whole cow, the gallbladder is bigger than the sky, and the heart is fine. ... It is easy to deal with, not swearing, secretly and not willing to vent, old adults and difficult, what is the situation? "[3]As a fantasy story, " The Son of a Businessman " vividly tells us that in the face of evil forces, as long as you have the courage, you will use your strategy and you will be able to win.

The novels that express children's wit also include "Shepherd" in "Strange Tales from a Lonely Studio". This novel writes two shepherds to use their wisdom to skillfully use the old wolf to protect the nature of the young wolf, so that the old wolf runs back and forth between the two trees. Exhausted, the old wolf will be exhausted. This article also conveys such information. For a ferocious and harmful thing like a wolf, as long as you dare to fight and be good at fighting, you can still win by war. However, the behavior of the two shepherds in this article is more or less a child's prank, and the means used are cruel, which is not comparable to Jia Er's behavior of mentally removing the harlot fox for revenge and justice. This should be different.

\section{PU SONGLING'S VIEW ON CHILD EDUCATION}

$\mathrm{Pu}$ Songling's imperial examinations have repeatedly failed, and most of his life was spent in the countryside of Luanchuan. As a private teacher with more than 30 years of teaching experience, $\mathrm{Pu}$ Songling has not left the education thoughts of future generations, but he has always been concerned about the education of young people. In his poems and "Strange Tales of Liaozhai" In the "Different", we can understand his insights into the education of young people from the side. In his "Ghost Story", there are more than a dozen poems that he tells his children and grandchildren how to learn and how to behave. For example, in the "Showing Children" article, there is such a sentence with a strong heart and mind: "After all, you will grow up, not a shackle." Do not hesitate to divide the yin, but also to solve the problem. The red window is still high, and there is no lung and liver! ... There are battalions in life, will you be an official? But the ability to farmer mulberry can also be a fight. Wandering and eating, good food? ... Read this heart, 
say it! "[4] In his poems, he used "sentences that are difficult to violate, and people are more self-motivated" [5]. This sentence encourages children and grandchildren to be aggressive and self-motivated. In many chapters of "Strange Tales from a Lonely Studio", Pu Songling has intentionally or unintentionally touched on the issue of youth education. The most typical one is the popular "Detailed Willow", which is shown by the young woman in the novel. The educational method adopted is exactly the same as the "frustration education" that is strongly advocated today. In the education of young people, the spirit of active resistance advocated and promoted by $\mathrm{Pu}$ Songling should also attract enough attention. Like several works mentioned above, Pu Songling passed $\mathrm{Yu}$ Jiang, Shang Sanguan, Jia Er and other teenagers. The image of the hero, the message to the reader is intriguing.

In the era of the cruel autocracy and strong tyranny of $\mathrm{Pu}$ Songling's life in the early Qing Dynasty, bureaucratic rulers and bully nostalgia arbitrarily oppressed and abused the lower class, and the people were unable to uphold justice. $\mathrm{Pu}$ Songling was in many chapters of Strange Tales from a Lonely Studio. Some performance. In the face of social injustice and infringement of power, $\mathrm{Pu}$ Songling seems to seldom preach the philosophy of life that is reluctant to accept (the other is to write the filial piety theme), but actively advocates to rise up and fight. Pu Songling's personal character has a very valuable character of active resistance and a violent and arrogant heroic. In the impression of the average person, $\mathrm{Pu}$ Songling seems to always appear in the image of a weak teacher, but it cannot be ignored that $\mathrm{Pu}$ Songling's character also lacks the qualities of straightness, strength, and courage to fight and the good fortune. The spirit of chivalry. His son $\mathrm{Pu} \mathrm{Pu}$ said that he was "only instinctual, straightforward, not refusing to blame, not a noble, that is, the plain friendship, such as sorrow, and the emotions of the flesh and blood, the force of the party, the face and the court, even tired It's straightforward, not embarrassing to the recipient, and my father's arrogance is so good that I have no good friends. "[6] He has written a book, criticizing Sun Hao, who is both a big official and an old friend, indulging himself in the hometown; he used to be outrageous and wrote a letter blaming Wang Luzhan, a friend who did not honor his parents; he once asked for help. In the face-to-face struggle with the then Suichuan glutinous rice, the latter was "speaking poorly" [7], and under his resolute struggle, the corrupt official Conley was finally dismissed for corruption.

In many chapters of "Strange Tales from a Lonely Studio", he expresses people's resistance and struggle spirit through vivid images and tortuous storylines. Of course, due to the excessive power of dark reality, he often uses ideas to illusion. Deformed into a class with powerful energy to complete revenge. Representative articles in this regard include "Xiang Yu" (revenge by the Huahu), "Bo Xing female" (borrowing the dragon to avenge). His young heroes Yu Jiang, Shang Sanguan, Jia Er in the face of evil forces, whether it is the fierce animal of nature, or the human bully, or the surreal world of the fox monster, all bravely fight, And the battle won. He tells people with such stories, especially telling young children that when confronted with infringement, they must fight bravely and never accept it. In the "Three Officials of the Shang Dynasty", he said, "I hope that the people in the world will buy silk and embroider, and their merits will not be reduced to Feng Zhuang." It is also hoped that young women will be active. Rebellious business trio learning. Pu Songling's view of children's education is undoubtedly positively inspiring for our education of the younger generation today.

The Chinese nation has always been a nation that dares to resist foreign aggression and dare to fight against aggression. However, there is no need to say that because of the historical society and other reasons, our national character has always had the character weakness of obedience, obedience, and numbness. Mr. Lu Xun once With the sorrow of his misfortune, anger and disapproval, he expressed his deep feelings of facing the weakness of this nation, and there is no coincidence. $\mathrm{Pu}$ Songling also had similar views with $\mathrm{Mr}$. $\mathrm{Lu}$ Xun in the novel. In "Strange Tales from a Lonely Studio", there is a "Black Beast" article, which is extremely short and tells the story of a tiger encountering an unknown black beast, which is against the tremor and the death of the neck. Although the story is short, he has a short discussion in the later "Di Shi Shi", profound and painful:

Different history: "The beast does not know what the name is, but asks its shape, no more than the tiger, and what is the death of the neck, what is the fear?" Everything has its own system and it is unsolvable. If you are the most fearful, when you see it, you will be in groups of ten, and you will not be able to marry. Concentrate on the eyes, listen to the sputum, and use the claws to lick its fat; the fat is to the top of the stone. I am wearing a stone and squatting, but I am afraid of falling. Qi Zhi has already taken the stone to eat, and Yu Shi is scattered. I have tasted greed and sorrow, and it is also a slap in the face of the fat and sorrow of the people, and it is already a slap in the face; but it is already a sigh of relief. Can you mourn!"

The tiger faced the black beast and said, " Don't dare to breathe while listening to food." The author then turned his head and said, " The love of Chi is still the same. "You can be a husband," and " Chi Chi " here means the group and the people. In Pu Songling's view, how obedient and submissive the common people under the rule of high pressure are like tigers obedient to black beasts, and how similar it is to $\mathrm{Lu}$ Xun's famous " mourning his misfortune, anger his irrefutability". Pu Songling was impressed by the weakness of the common people's character that they were submissive and did not dare to resist. In his novels, he intentionally strengthened his sense of resistance and struggle, both in shaping the image of adults and children. Although his ideological significance could not be compared with that of $\mathrm{Lu}$ Xun's novel " Scream", it was also commendable in the era in which $\mathrm{Pu}$ Songling lived.

Although there are many excellent contents and practices in the education tradition of children in ancient China, it goes without saying that there are also many negative things, such as instilling "three cardinal guides and five permanent members" and " three principles and four virtues" into children, educating children with" foolish loyalty and foolish filial piety" and declaring" obeying the orders of heaven and observing oneself". Our folk proverbs are also full of instructions such as "harmony for your own sake", "forbearing 
for your own sake", "stepping back from the sea and widening the sky" and even" self - help for your own sake". Most of the children raised are obedient and submissive " little sheep" and grow up. Mr. Lu Xun was deeply impressed by the article "From the Children's Photography": "Tame is not evil." But development is going to go on, everything is tamed, but it is by no means a virtue. Maybe it is nothing. "[8] Lu Xun has always opposed the old-fashioned education of feudalism. He criticized the traditional malpractices of youth education in the article "Children in Shanghai" and said: "There is a cold reception or swearing, and even a fight, which makes him fearful and retreat, as if he were a slave. One is awkward, but the parents are beautifully known as 'obedient'. They think it is the success of education. When they let him go outside, if they are out of the cage, he will never fly or jump. "[8] In the ancient Chinese education tradition, there was a lack of content to actively fight against the evil forces. It cannot be said that this is a relatively large defect in the ancient children's education tradition.

Active awareness of resistance is a valuable spiritual quality. Comrade Mao Zedong repeatedly praised the "hard bones" spirit of Mr. Lu Xun's body that did not have a trace of slavery and sorrow, and Mao Zedong himself also had the spirit and courage to face the unyielding and determined struggle against power. As early as 1939, in the face of the anti-communist forces in the Kuomintang, which was constantly engaged in friction, Mao Zedong once said arbitrarily that "people do not commit me, I do not commit crimes; if people commit me, I will commit crimes" [9] On the layered blockade of imperialism represented by the United States, he also replied with sorrow: "The blockade, the blockade for ten years and eight years, all problems in China have been resolved. Will the Chinese cower before difficulties when they are not afraid even of death? [10] showed a strong and unyielding spirit of resistance and admirable national integrity, and the great war of resistance against the United States and aided by the world shocked the great man's words. It is not terrible that a nation is materially weak, because it can be changed through hard work; spiritual stupidity is truly terrible, which means that this nation will lose its future and lose hope. The same is true of one person. Only with the spirit of bravery and fearlessness and active resistance can we bravely defend our legitimate rights and interests, and we can not be afraid of power, be proactive, and stand on our own feet.

\section{CONCLUSION}

Young people are the future of the country and the nation. $\mathrm{Mr}$. Lu Xun has always strongly encouraged young people to be "real warriors", "dare to face the bleak life, dare to face the blood of the drowning" [11], and this spirit of active struggle is war. The times are still peaceful years, and they should be cultivated vigorously. Therefore, in today's increasingly intensified international competition, in the effort to realize the great "Chinese Dream" today, cultivating a generation of young people with a positive sense of resistance is also an era of the country's and the country's need for a strong and revived era. In this sense, studying and exploring the spirit of active resistance in Pu Songling's children's novels is particularly inspiring for our youth education today.

\section{ACKNOWLEDGMENT}

Mailing address: No. 1 Bei'an Road, Zaozhuang City, Shandong Province; Zip code: 277160

\section{E-Mail: sdzzyyj@163.com}

About the Author:

Yang Yujun: Male, born in July 1963, graduated from the Chinese Department of Shandong Normal University in 1984, and obtained a Master of Arts degree from Beijing Normal University in 2004. Currently working in the School of Elementary Education, Zaozhuang College, associate professor. He devoted himself to the study of ancient novels and education and teaching, focusing on $\mathrm{Pu}$ Songling and Strange Stories from a Lonely Studio, and published many research articles.

\section{REFERENCES}

[1] Jiang Feng. History of Modern Chinese Children's Literature [M], p. 4. Shijiazhuang: Hebei Children's Publishing House, 1986.

[2] Zhang Youhe. Liaozhai Zhiyi Association Conference Note [M], 376 pages. Shanghai: Shanghai Ancient Books Publishing House, 1978.

[3] Zhang Youhe. Commentary on the Liaozhai Symposium Conference [M], 129 pages. Shanghai: Shanghai Ancient Books Publishing House, 1978.

[4] Pu Songling. Show Zhu Er.// Sheng Wei. Complete Works of Pu Songling [M], total 1745 pages. Beijing: Xuelin Press, 1998.

[5] Pu Songling. Xi Li De Cai Qin.// Sheng Wei. Complete Works of Pu Songling [M], total 1917 pages. Beijing: Xuelin Press, 1998.

[6] Pu Wei. Liu Quan Gong Xing. / / Zhu Yixuan. Liaozhai Zhiyi data compilation [M], 283 pages. Tianjin: Nankai University Press, 2002.

[7] Pu Songling. Also cast Yu County public presentation. // Sheng Wei. Complete Works of Pu Songling [M], total 1237 pages. Beijing: Xuelin Press, 1998.

[8] Lu Xun. Complete Works of Lu Xun [M], 81. Beijing: People's Literature Publishing House, 1998.

[9] Mao Zedong. Talks with the reporters of the Central News Agency, the Sweeping Newspaper, and the Xinmin Daily. //Selected Works of Mao Zedong (Volume 2) [M], 590. Beijing: People's Publishing House, 1991.

[10] Mao Zedong. Don't, Stuart. //Selected Works of Mao Zedong (Volume 4) [M], 1496. Beijing: People's Publishing House, 1991.

[11] Lu Xun. Commemorating Liu Hezhen Jun // Complete Works of Lu Xun (Volume III) [M], 274 pp. Beijing: People's Literature Publishing House, 1998. 